\title{
Utilization of Demolished Concrete Waste for New Construction and Comparing Their Compressive Strength after 28 Days with Normal Aggregate Concrete
}

\author{
Mrs. Bharti Manjhi ${ }^{1}$, Mrs. K Divya Kotecha ${ }^{2}$, Ms. Anisha Mire ${ }^{3}$, Dr. Lokesh singh ${ }^{4}$ \\ ${ }^{1}$ Student of M.tech Structural Engg. ${ }^{2,3}$ Asst.Prof. , Dept of Civil Engg. RSR-RCET,Bhilai. \\ ${ }^{4}$ Head of Civil Dept RSR-RCET, Bhilai
}

DOI: 10.46335/IJIES.2020.5.8.1

\begin{abstract}
The mass production of construction and demolition are creating serious problems in India. In most of the countries applicability of construction and demolished wastes are restricted to non-structural concrete, pavements and backfilling. In present day Demolished Concrete waste handling and management is challenging one in all over the countries in the world. Recycle the demolished concrete has reduces the environmental pollution and protect the natural resources. In this research paper an experimental study is carried out to investigate the recycling of demolished waste concrete for new construction. This research included a collecting a Demolished Concrete from waste and is separated with different sizes using sieve analysis. Various sizes of aggregate is treated with heating process. Finally the demolished concrete aggregate DCA is replaced by various percentage of $10 \%, 20 \%, 30 \%, 50 \%, 100 \%$ and test can be conducted and compared with nominal concrete.
\end{abstract}

\section{I- INTRODUCTION}

\subsection{Background}

C oncrete is versatile it's durability, sustainability, and economy have made it the world's most widely used construction material. About four tons of concrete are produced per person per year worldwide. The term concrete refers to a mixture of aggregates, generally sand, and either gravel or crushed stone, held together by a binding material of cementations paste. Understanding the fundamentals of concrete is necessary to produce quality concrete according to design for the construction of durable structure.

\subsection{Essentials of Quality Concrete}

Workmanship, mix proportions, material characteristics, and adequacy of curing is related to performance of concrete. The production of quality concrete involves a variety of materials and a number of different processes including, the production and testing of raw materials, determining the desired properties of concrete, proportioning of concrete constituents to meet the design requirements, batching, mixing, and handling to achieve consistency, proper placement, finishing, and adequate consolidation to ensure uniformity, proper maintenance of moisture and temperature conditions to promote strength gain and durability, and finally, testing for quality control and evaluation. Many people with different skills come into contact with concrete throughout its production. Ultimately, the quality of the final product depends on their workmanship. It is essential that the workforce be adequately trained for this purpose. When these factors are not carefully controlled, they may adversely affect the performance of the fresh and hardened properties. 


\subsection{Defined Materials}

Concrete becomes hard on drying it is basically a mixture of two components: aggregates and binder paste. The binding paste, comprised of portland cement and water, binds the aggregates (usually surkhi or sand and crushed stone or gravel) into a rocklike mass as the paste hardens from the chemical reaction between cement and water. Supplement cementitious materials and chemical admixtures can also be included in the paste to improve the quality of concrete. The paste may also contain entrapped air or purposely entrained air. The paste constitutes about $25 \%$ to $40 \%$ of the total volume of concrete. Figure 1shows that the absolute volume of cement is usually between $7 \%$ and $15 \%$ and the water between $14 \%$ and $21 \%$. Air content in concrete ranges from about $4 \%$ to $8 \%$ of the volume.

\subsection{Introduction to Construction and Demolition Waste}

Balance of the supply of construction and demolition (C\&D) wastes and the demand of recycled C\&D waste products (Balance Theory) is an effective means of reducing these wastes. The maturity of Balance Theory requires gradual establishment of recycling facilities. These facilities are capable to accept and handle not only inert materials but also other C\&D wastes - wood and wood products, cardboard, metal, and plastics. The Balance Theory requires construction workers to adopt the idea of reduction of wastes. They are educated to clean their working places constantly and collect all construction wastes they generated into separate collection spots within the construction site. A site management personnel is required to establish site facilities and set up conditions in employment contracts, and subcontracts for workers, and subcontractors to follow. The culture of separating wastes at sources must be established and widely adopted so that Balance Theory could be realized. Balance Theory advocates the amount of wastes generated from a construction project, and sent for recycling process must be equivalent (or proportional) to the amount of the recycled C\&D products imported and used as construction materials for that project. Levels of waste within the construction industry need to be reduced for environmental and economic reasons.

\subsection{Present Scenario of Demolished Waste used in India}

Construction and demolition waste (C\&DW) management is gaining attention from policy makers in India. This article estimates C\&DW generation from urban building, rural building, and non-building sectors in India and calculates material, energy, and emissions savings from C\&DW recycling. The method used in this study is top down up material flow analysis approach. The results indicate that India generated between 112 and 431 million tonnes of C\&DW in 2016 depending upon the assumptions, which are orders of magnitude higher than official records indicate. Although per capita waste generation from rural area is less than urban areas, rural areas as a whole generate more waste than urban areas, as rural population is still over two times the urban population in India. Additionally, it was estimated that formal C\&DW recycling can save upto $2-8 \%$ of natural minerals, such as sand and aggregate in urban areas, energy and emissions savings were negative, implying that recycled C\&DW materials are likely to be more resource and environmentally intensive as compared to natural materials.

\subsection{Demolished waste of concrete as a material}

Recycling of concrete debris can make a contribution to reducing the total environmental impact of the building sector. To increase the scope for recycling in the future, aspects of recycling have to be included in the design phase. Besides, aggregate sources near Metro Manila are almost depleted, so aggregates have to be brought from far quarries. Consequently, reclaiming aggregates from concrete debris would lead to environmental and economic benefits.

\section{II- LITERATURE REVIEW}

\subsection{Significance of concrete as construction material}

The uses of Reinforced Concrete in India in general, most references to pre-twentieth century concrete buildings. In India are for unreinforced concrete An example is "Concrete-Building at Shimla, India" published in 1886 that refers to the construction of two large buildings, the Sectariait and the Army Headquarters " Both are Ron-framed structures using mass concrete for the foundations, walls, and floors formed by cashing concrete onto curved corrugated uon sheets that spanned between beams. The concrete was made manually on site from lime burnt in local lumps and crushed stones. There are some examples of reinforcement in concrete foundations such as the hooplron put in the concrete foundations of the High Court in Calcutta but the real use of reinforced concrete began with the Royal Engineers $m$ the first years of the twentieth century ZS The majesty of contemporary accounts in architectural and enginemen journals on the 
use of reinforced concrete In India refer to its use in buildings, structures and civil engineering works such as roads and bridges. It was, however, extensively employed for more mundane items such as lamp and fence posts, and railway sleepers. There was also mentions that India should build reinforced concrete sleepers for the coastal trade to save on imported steel. The following 1s a summary of buildings and enginemen structures and other miscellaneous uses, selected to illustrate the various forms and applications of reinforced concrete."

Concrete is used in such large amounts because it is, huge quantities of construction materials are required in developing countries due to continued infrastructural growth and also huge quantities of construction and demolition wastes are generated every year in developing countries like India. The disposal of this waste is a very serious problem because on one side it requires huge space for its disposal while on the other side it pollutes the environment. In recent years demolished concrete waste handling and management is the new primary challenging issue faced by the countries all over the world. It is very challenging and hectic problem that has to be tackled in an indigenous manner, it is desirable to completely recycle demolished concrete waste in order to protect natural resources and reduce environmental pollution. In this research paper an experimental study is carried out to investigate the feasibility and recycling of demolished waste concrete for new construction. The present investigation to be focused on recycling demolished waste materials in order to reduce construction cost and resolving housing problems faced by the low income communities of the world. This investor concluded that demolished aggregate posses relatively lower bulk crushing, density and impact standards and higher water absorption as compared to natural aggregate. The compressive strength of the concrete is decreases with increasing the percentage of demolished material from $0 \%$ to $50 \%$. The 28 days tensile strength of the concrete is decreases with increasing the percentage of demolished material.

In present day Demolished Concrete waste handling and management is challenging one in all over the countries in the world. Recycle the Demolished Concrete has reduces the environmental pollution and protect the natural resources. This research is focused on utilising the Demolished Concrete waste and reduces the generation of construction waste. This research included a collecting a Demolished Concrete from the demolition of building at site, Crushing Demolished Concrete waste and is separated with different sizes using sieve analysis. Various sizes of Aggregate is treated with heating and chemical process. Finally the Demolished Concrete
Aggregate (DCA) is replaced by various percentages of $10 \%, 20 \%, 30 \%$ adding with fibre and test can be conduct and compared with nominal Concrete.

Based on the experimental investigations carried out, the following conclusions are drawn On Comparing Compressive strength of Nominal Concrete and Demolished Concrete Aggregate, the percentage of DCA replacement upto $20 \%$, the strength increased as $2.5 \%$. On Comparing Split Tensile Strength of Nominal Concrete and Demolished Concrete Aggregate, the percentage of DCA replacement upto $20 \%$, the strength increased as $7.07 \%$. On Comparing Flexural strength of nominal Concrete and Demolished Concrete Aggregate, the percentage of DCA replacement Reducing the strength from the study the Replacement of DCA Concrete allowed to use up to $20 \%$ with adding fiber. For more replacement of DCA Concrete has decreasing in strength.

Environmental issues such as climate change and associated global warming, depletion of natural resource and biodiversity, water and soil pollution, generation of huge amount of waste materials and their disposal are some of great challenges faced by present day civilization. Recycling of materials and reuse of the material is very important. Recycled concrete aggregates are used in concrete in replacement of nominal concrete aggregates $20 \mathrm{~mm}$ and grit aggregates, replacement of $50 \%$. Different various percentage of aggregate replacement gives optimum replacement content $50 \%$ in mix design of M20 without admixture using. Compressive strength of cubes are $20 \%$ more than nominal concrete cubes and getting strength $30 \mathrm{KN} / \mathrm{mm} 2$ nominal mix design at 28 day and $25 \mathrm{KN} / \mathrm{mm} 2$ for replacement of 50\% recycled aggregate in M20 design. For same way in 56 days result analysis compressive strength $25 \%$ increased than nominal mix design, compressive strength is $25 \mathrm{KN} / \mathrm{mm} 2$ and $28 \mathrm{KN} / \mathrm{mm} 2$ for nominal M20 and 50\% replacement of recycled aggregate M20. Split tensile cylinder test result shows almost $10 \%$ and $15 \%$ increase in recycled aggregate concrete to nominal concrete at 28 day and 56 day result. Flexural strength of beams test result show that $20 \%$ and $15 \%$ increase in recycled aggregate concrete to nominal concrete aggregate at 28 day and 56 day result analysis. All result data comparison to NDT test of rebound hammer is done. Using recycled aggregate in concrete, is best way to recycled demolished concrete and achieve the strength better than nominal concrete aggregates. The different result of compressive strength of 3 day, 28 day and 56 day show that replacement of recycled aggregate of $50 \%$ to achieve the M20 and get higher strength than nominal concrete. Split tensile strength and flexural strength gives almost same result and without 


\section{International Journal of Innovations in Engineering and Science, Vol 5, No.8, 2020}

\section{www.ijies.net}

admixture M20 strength can achieved. At the end comparison with compressive strength to rebound hammer number gives better analysis to understand comparison of NDT and mechanical test analysis.

\subsection{Conclusion Of Literature Review}

Many researchers have worked in this field some had collected the information about the production of demolished waste in different area, huge amount of waste is degraded in India also ; some of them worked in the replacement of coarse aggregate with demolished waste in some percentage only; some of them founded the strength benefits using this waste and many more about different properties of concrete for eg : durability, flow ability, workability, tensile strength etc., Here I found a big research gap about the $100 \%$ replacement of Coarse aggregate with demolished waste whether it is possible to gain suitable strength or not.

\section{III- CONCLUSION}

After studying the research journals in this topic the conclusions came to be are as under:

(1) Demolished aggregate posses relatively lower bulk crushing, density and impact standards and higher water absorption as compared to natural aggregate.

(2) Using demolished aggregate concrete as a base material for roadways reduce the pollution involved in trucking material.

(3) The compressive strength of the concrete is decreases with increasing the percentage of demolished material from $0 \%$ to $50 \%$.

(4) The split tensile strength of demolished concrete is also decreases with increasing the percentage of demolished material.

(5) The 28 days tensile strength of the concrete is decreases with increasing the percentage of demolished material.

(6) The use of dismantled aggregate in making fresh concrete will also help in reduction of solid waste dumping on existing landfill sites.

(7) The reuse of dismantled concrete will help in improvement of overall environment of the region. Firstly by reduction in mining and secondly reduction in air pollution resulting from production of aggregates (dust pollution) and transportation of aggregate from mining to consumption point (vehicular pollution).

(8) The idea of reusing the waste material is very exciting and encouraging specially when it will be helpful in minimizing destruction to earth's crust and green forest cover by virtue of reduced mining.

(9) Based on the experimental investigations carried out, the following conclusions are drawn On Comparing Compressive strength of Nominal Concrete and Demolished Concrete Aggregate, the percentage of DCA replacement upto 20\%, the strength increased as $2.5 \%$. On Comparing Split Tensile Strength of Nominal Concrete and Demolished Concrete Aggregate, the percentage of DCA replacement upto $20 \%$, the strength increased as $7.07 \%$. On Comparing Flexural strength of nominal Concrete and Demolished Concrete Aggregate, the percentage of DCA replacement Reducing the strength From the study the Replacement of DCA Concrete allowed to use up to $20 \%$ with adding fiber. For more replacement of DCA Concrete has decreasing in strength.

(10) Using recycled aggregate in concrete, is best way to recycled demolished concrete and achieve the strength better than nominal concrete aggregates. The different result of compressive strength of 3 day, 28 day and 56 day show that replacement of recycled aggregate of $50 \%$ to achieve the M20 and get higher strength than nominal concrete. Split tensile strength and flexural strength gives almost same result and without admixture M20 strength can achieved. At the end comparison with compressive strength to rebound hammer number gives better analysis to understand comparison of NDT and mechanical test analysis.

(11) With increase in water/cement ratio from 0.5 to 0.55 , there is an increase in compressive strength of both concretes.

(12) With the increase in water/cement ratio from 0.55 to 0.60 , natural aggregate concrete shows reduction in compressive strength whereas discarded/recycled aggregate concrete shows increase in compressive strength.

(13) With the increase in water/cement ratio from 0.60 to 0.65 , there was a reduction in compressive strength of both concretes.

(14) At higher water/cement ratios (0.65) the compressive strength of discarded concrete is close to that of natural concrete at all curing level $(7,14$, 21 , and 28 days). Specifically at day 28 day the compressive strength of discarded concrete attained $84.7 \%$ while virgin concrete recorded 84.37 . This trend indicates with increase in water/cement ratio the compressive strength of discarded/recycled aggregate concrete may likely attain the same compressive strength standard. 


\section{REFERENCES}

[1] Utilization of demolished concrete waste for new construction katam avinash, sri dumpa venkateswarlu.

[2] Utilization of demolished concrete waste for new construction and evaluation of its strength veeraselvam, dr. dhanalakshmi.g.

[3] Use of Demolished Concrete Materials in Concrete and Comparative Study of its Mechanical Properties: NDT Comparison Nikita Patel, Dr. Piyush Patel.

[4] Recycling Of Concrete Waste Material From Construction Demolition Aiyewalehinmi E.O1 and Adeoye T.E

[5] Applicability of Construction and Demolition Waste Concrete in Construction Sector - Review Avindana John I\& Dr. Suhil Kumar Mittal, N.K Dhapekar.

[6] $\operatorname{Dr}$ A. K. Mullick "Management of Construction and Demolition Waste- Current Status,” (2014), Indian Building Congress.

[7] Praveen Mathew, Shibi Varghese, Thomas Paul, Eldho Varghese, Recycled Plastics as Coarse Aggregate for Structural Concrete, International Journal of Innovative Research in Science, Engineering and Technology, Vol. 2, Issue 3, March 2013, ISSN: 2319-8753

[8] L.R. Manjunatha, Sandhya. R. Anvekar, M.V. Yogananda , Recent Developments In The Indian Concrete Industry In The Use Of Ggbs In Concrete At Rmc Batching Plants As Partial Replacement To OPC Cement And Its Effects On Concrete Durability And Sustainabilty in The Indian Context.

[9] Vipul D. Prajapati, Nilay Joshi, Prof. Jayesh kumar Pitroda,Used Foundry Sand: Opportunities For Developing Of Low Cost Rigid Pavement.

[10] P. Kumar Mehta and Richard W. Burrows Building durable structures in the 21 st century July $2001 *$ The Indian Concrete Journal 437443.

[11] Salihu AndaaYunusam The Importance Of Concrete Mix Design (Quality Control Measure), Volume Journal of Engineering and Applied Sciences 3, December 2011, Department of Civil Engineering Kaduna polytechnic, Kuduna. 